\title{
Meaning of tumor protein 53-induced nuclear protein 1 in the molecular mechanism of gemcitabine sensitivity
}

\author{
NAOKI NAKAYA $^{1 *}$, YASUHITO ISHIGAKI $^{2 *}$, HIDEO NAKAJIMA $^{1,3}$, MANABU MURAKAMI $^{2}$, \\ TAKEO SHIMASAKI ${ }^{1}$, TAKANOBU TAKATA ${ }^{2}$, MAMORU OZAKI ${ }^{2}$, NELSON J. DUSETTI ${ }^{4}$, \\ JUAN L. IOVANNA ${ }^{4}$ and YOSHIHARU MOTOO ${ }^{1}$ \\ ${ }^{1}$ Department of Medical Oncology, ${ }^{2}$ Medical Research Institute, Kanazawa Medical University, \\ Uchinada, Ishikawa; ${ }^{3}$ Department of Oncology, Ageo Central General Hospital, Ageo, \\ Saitama, Japan; ${ }^{4}$ Stress Cellulaire, INSERM U624, Marseille, France
}

Received May 22, 2012; Accepted July 10, 2012

DOI: $10.3892 / \mathrm{mco} .2012 .8$

\begin{abstract}
Stress proteins of the pancreas, such as tumor protein 53-induced nuclear protein 1 (TP53INP1), are important factors in the invasion and metastasis of pancreatic cancer. TP53INP1 is a pro-apoptotic factor and is transcriptionally regulated in p53-dependent and -independent manners. A previous study proved that gemcitabine induces TP53INP1 expression in pancreatic cancer cells and the pancreatic cancer cell line (PANC-1). The present study aimed to clarify the association between TP53INP1 and gemcitabine sensitivity. The expression of TP53INP1 and its related factors, such as cell growth and cell cycle status in TP53INP1-knockout mouse embryonic fibroblasts [TP53INP1 $1^{-1}$-mouse embryonic fibroblasts (MEFs)] to those in wild-type counterparts (TP53INP1 $1^{+/+}$-MEFs) were compared. Flow cytometric analysis demonstrated no difference of the checkpoint function in TP53INP $1^{-1-}$-MEFs and TP53INP $1^{+/+}$-MEFs when exposed to $10 \mathrm{ng} / \mathrm{ml}$ of gemcitabine. No significant difference was found in the level of p53 expression in the cell types, although the base level and gemcitabine-induced expression of p21 were significantly decreased in TP53INP1 ${ }^{-1}-$ MEFs, compared to those in wildtype counterparts. Results showed that gemcitabine induced the p21 expression in TP53INP1 $1^{+/+}$-MEFs, although not in TP53INP $1^{-/}$-MEFs. However, their respective cell-cycle checkpoints were not different. Therefore, TP53INP1 was found to be associated with drug sensitivity through control of the cell cycle.
\end{abstract}

Correspondence to: Dr Naoki Nakaya, Department of Medical Oncology, Kanazawa Medical University, 1-1 Daigaku, Uchinada, Ishikawa 920-0293, Japan

E-mail: n-naoki@kanazawa-med.ac.jp

*Contributed equally

Key words: gemcitabine, tumor protein 53-induced nuclear protein 1, p21, p53, cell cycle

\section{Introduction}

Pancreatic cancer is a highly lethal disease. Approximately 227,000 individuals succumb to the disease annually throughout the World. The prognosis of pancreatic cancer is poor, with a 5 -year survival rate of $5 \%$ or less (1). The surgery adaptation is $20 \%$ or less in newly diagnosed cases of pancreatic cancer (2). Pancreatic cancer cells have aggressive biological characteristics, while the antitumor effects of radiation and chemotherapy are insufficient to treat the disease (3).

Gemcitabine [2',2'-difluorodeoxycytidine $(\mathrm{dFdC})]$, a nucleic acid analogue, is one of a few chemotherapeutic drugs used in the treatment of pancreatic cancer. Regarding the action mechanism, gemcitabine is metabolized to $\mathrm{dFdC}$ diphosphate (dFdCDP) and dFdC triphosphate (dFdCTP) in the cells (4). Since dFdCTP are incorporated into the DNA strand by DNA polymerase, DNA replication is obstructed. After that, apoptosis is induced (5). Consequently, the dCTP density in the cells is decreased. In addition, gemcitabine inhibits ribonucleotide reductase (6). Consequently, DNA synthesis is decreased.

Deletion, amplification and methylation of DNA are important for pancreatic cancer tumor development and progression $(1,2)$. Pancreatitis-associated protein (PAP), a pancreatic stress protein, is induced in pancreatic acinaracinar cells in acute pancreatitis, demonstrating anti-apoptotic as well as anti-inflammatory actions (7). Ectopic PAP expression was detected in pancreatic ductal adenocarcinoma (8). Additionally, PAP levels in serum (9) and pancreatic juice (10) were increased in pancreatic cancer. Pancreatic stress proteins, other than PAP, include p8 and tumor protein 53-induced nuclear protein 1 (TP53INP1). The actions of $\mathrm{p} 8$ resemble those of PAP. Notably, p8 is crucial in the gemcitabine resistance (11).

However, TP53INP1 expression decreases in cancer cells, as well as having a tumor suppressor gene character (12-14). TP53INP1 protein expression is induced in a gemcitabinetreated pancreatic cancer cell line (PANC-1) (15), therefore, an association between the gemcitabine sensitivity of pancreatic cancer and TP53INP1 was suspected. The p53 gene is mutated in most human cancer cells, including pancreatic cancer. TP53INP1 is closely correlated with p53, with a pro- 
apoptotic potential (12). TP53INP1 controls transcriptional activities of $\mathrm{p} 53$ by homeodomain-interacting protein kinase 2 (HIPK2) (16). Overexpression of TP53INP1 stops the cell cycle, while inducing cell apoptosis (17).

The present study was conducted to clarify the molecular mechanisms of gemcitabine sensitivity regarding TP53INP1. Moreover, the significance of TP53INP1 in cell cycles, check points and gemcitabine sensitivity was delineated.

\section{Materials and methods}

TP53INP1 $1^{-/}$and TP53INP1 ${ }^{+/+}$mouse embryonic fibroblasts (MEFS).TP53INP1-deficient mice were generated as described previously (18). At 14.5 days post coitum, TP53INP1 ${ }^{-/}$-MEF and TP53INP1 ${ }^{+/+}$-MEF were prepared from embryos derived from the homozygous breeding of TP53INPI-deficient mice and of their wild-type littermates, according to earlier reports in the literature $(12,14,19)$. These cells were transformed and immortalized by transduction with the pBabe-E1A/ras V12 retroviral vector, encoding the constitutively active ras. The TP53INP1 genotypes of the respective MEFs were determined by polymerase chain reaction (PCR). Genotype analyses were conducted on genomic DNA from MEF, with the following PCR primers F, R1 and R2: F, 5'-AATGTATGCAATCTTAGCTGA TGC-3'; R1: 5'-TCTTGAGGTAACATAGTGAAATGC-3'; and R2: 5'-CCAAACACTGTCACTGTATTGATA-3'. PCR analysis was performed as described in an earlier study (18).

Cell culture and treatment. TP53INP1/--MEF and TP53INP1 $1^{+/+}$-MEF were maintained in Dulbecco's Modified Eagle's Medium (DMEM) Glutamax medium supplemented with $10 \%$ fetal bovine serum (FBS) and $1 \%$ penicillin/streptomycin (Invitrogen Corp., Groningen, The Netherlands) at $37^{\circ} \mathrm{C}$ under $5 \%$ in $\mathrm{CO}_{2}$ atmosphere. The ras-transformed MEFs at early passages were used for subsequent experiments.

TP53INP1 $1^{-/}$-MEF and TP53INP1 ${ }^{+/+}$MEF were treated with $0,5,10$ and $20 \mathrm{ng} / \mathrm{ml}$ gemcitabine (Eli Lilly and Co., Indianapolis, IN, USA) for $24 \mathrm{~h}$.

Western blot analysis. Whole cell lysates were prepared using RIPA buffer with a protease inhibitor cocktail (Roche Diagnostics KK, Basel, Switzerland). A $25 \mu \mathrm{g}$ aliquot of each cellular protein sample was diluted in loading buffer (Bio-Rad Laboratories, Inc., Berkeley, CA, USA). The proteins were separated in sodium dodecylsulfate-polyacrylamide gel electrophoresis (SDS-PAGE) and transferred to Immobilon-P polyvinylidene fluoride 7 (PVDF) membranes (Millipore Corp., Billerica, MA, USA). Subsequent to blocking with $5 \%$ skimmed milk solution, the membrane was treated with monoclonal antibodies against p21, p53, TP53INP1 (Abcam, Cambridge, UK), Rb (Cell Signaling Technology, Inc., Beverly, MA, USA), and $\beta$-actin (Sigma-Aldrich Corp., St. Louis, MO, USA). A Cell Cycle/Checkpoint Antibody Sampler kit (Cell Signaling Technology, Inc.) was also used. The respective bound antibodies were detected with an IgG rabbit monoclonal antibody (SouthernBiotech, Birmingham, AL, USA), then visualized with Immune Star LD (Wako Pure Chemical Industries, Ltd., Osaka, Japan), using Fuji Xerox LAS4000 image analyzer (Fujifilm Corp., Tokyo, Japan). The intensity of each protein signal was measured using Multi Gauge ${ }^{\circledR}$ (Fujifilm Corp.).
Reverse transcription-PCR (RT-PCR). Total RNA was extracted from TP53INP1 $1^{-/}-\mathrm{MEF}$ and TP53INP1 $1^{+/+}-\mathrm{MEF}$, using an RNeasy Mini kit (Qiagen GmbH, Hilden, Germany). The RT reaction was conducted with a SuperScript ${ }^{\mathrm{TM}}$ III First-Strand Synthesis System (Invitrogen Corp.) using random hexamers to generate complementary DNA (cDNA) according to the manufacturer's instructions. RT-PCR was conducted using TaqMan probe; TaqMan ${ }^{\circledR}$ Fast Universal PCR Master mix (Applied Biosystems, Foster City, CA, USA). Sequences of the primers were CDKN1A (p21) mixed primers; Mm00432448_m1 (Applied Biosystems), glyceraldehyde-3-phosphate dehydrogenase (GAPDH) mixed primers; Mm99999915_g1 (Applied Biosystems). RT-PCR was conducted, using a Real-Time PCR system (Applied Biosystems 7900HT Fast; Applied Biosystems) as well as the $\triangle \triangle C T$ method. The result was analyzed with the SDS software ver. 2.3 (Applied Biosystems).

The same experiments were performed 3 times. The mean number of cells in each experiment was calculated with standard deviations (SDs).

Flow cytometry (FCM). The cells at the exponential growth phase were labeled with 5-bromo-2-deoxyuridine (BrdU) (Sigma-Aldrich Corp.) [1 mM dissolved in phosphate-buffered saline (PBS)] in a final concentration of $10 \mu \mathrm{M}$ in the medium. BrdU labeling and subsequent handling of the cells were conducted under subdued light. Subsequent to $15 \mathrm{~min}$ of incubation at $37^{\circ} \mathrm{C}$, the BrdU-containing medium was removed, and the cells were rinsed twice with PBS. The labeled cells were trypsinized and counted, using a hemocytometer and centrifuged at $5,000 \mathrm{x}$ g for $5 \mathrm{~min}$ at $4^{\circ} \mathrm{C}$. The pelleted cells were suspended and fixed in ice-cold $70 \%$ ethanol $\left(\sim 2 \times 10^{6}\right.$ cells $\left./ \mathrm{ml}\right)$ and stored at $-20^{\circ} \mathrm{C}$ until analysis.

The fixed cells were resuspended in $1 \mathrm{ml}$ PBS containing $0.5 \%$ Triton $\mathrm{X}-100$, treated with $2 \mathrm{~N}-\mathrm{HCl}$ for $30 \mathrm{~min}$ at room temperature and neutralized with $0.1 \mathrm{M}$ sodium tetraborate (pH 8.5). Subsequent to washing twice with washing solution [PBS containing $0.5 \%$ Tween- 20 and $1 \%$ bovine serum albumin (BSA)], the cells were stained with fluorescein isothiocyanate (FITC)-labeled mouse anti-BrdU antibody or FITC-labeled mouse $\operatorname{IgG} 1 \kappa$ isotype as a negative control (both antibodies included in FITC Mouse Anti-Human BrdU set; Becton-Dickinson, Franklin Lakes, NJ, USA) overnight at $4^{\circ} \mathrm{C}$. The stained cells were washed twice with $1 \mathrm{ml}$ ice-cold PBS and incubated with $0.25 \%$ RNase (Sigma-Aldrich Corp.) for $30 \mathrm{~min}$ at room temperature. The cells were then stained with $5 \mu \mathrm{g} / \mathrm{ml}$ propidium iodide (PI; Sigma-Aldrich Corp.) and examined using FCM (FACSCalibur; Becton-Dickinson) for green and red fluorescence, which determined the relative number of BrdU-labeled cells and cells examined, respectively.

Colony formation assay. A total of 200 exponentially growing $\mathrm{TP5} \mathrm{INP}^{-/-}$-MEFs or INP1 ${ }^{+/+}-\mathrm{MEFs}$ were seeded on a $6-\mathrm{cm}$ dish and grown in DMEM Glutamax medium, containing $10 \% \mathrm{FBS}$ at $37^{\circ} \mathrm{C}$ in a $5 \% \mathrm{CO}_{2}$ atmosphere. After a week, the colonies per dish were counted; each cell line was counted immediately.

When cells were confluent, gemcitabine was added to the medium 3 days subsequent to cell seeding. TP53INP1 $1^{-/}$and TP53INP $1^{+/+}$cells were treated with $0,5,10$ and $20 \mathrm{ng} / \mathrm{ml}$ 
$\mathbf{A}$

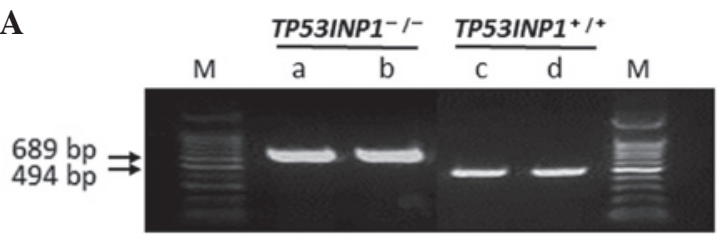

B

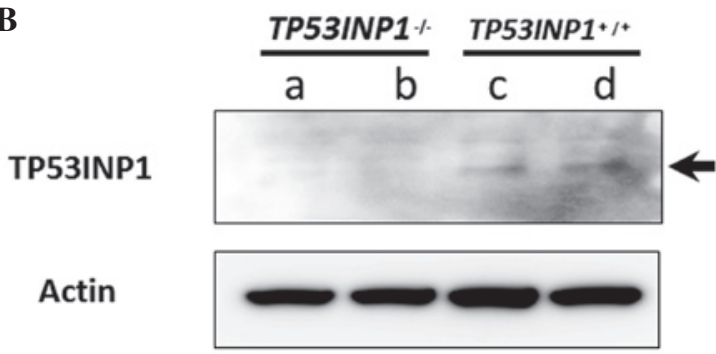

Figure 1. Confirmation of TP53INP1 expression. (A) Genotyping is shown. A band of $689 \mathrm{bp}$ in TP53INP1 ${ }^{-/}$cells and $494 \mathrm{bp}$ in TP53INP1 ${ }^{+/+}$cells were detected. (B) Western blot analysis of TP53INP1 protein. Western blot analysis demonstrates the expression of TP53INP1 protein of $27 \mathrm{kDa}$ in $\mathrm{TP}_{3} \mathrm{INP1}^{+/+}$cells, although no expression was found in TP53INP1 ${ }^{-/}$cells.

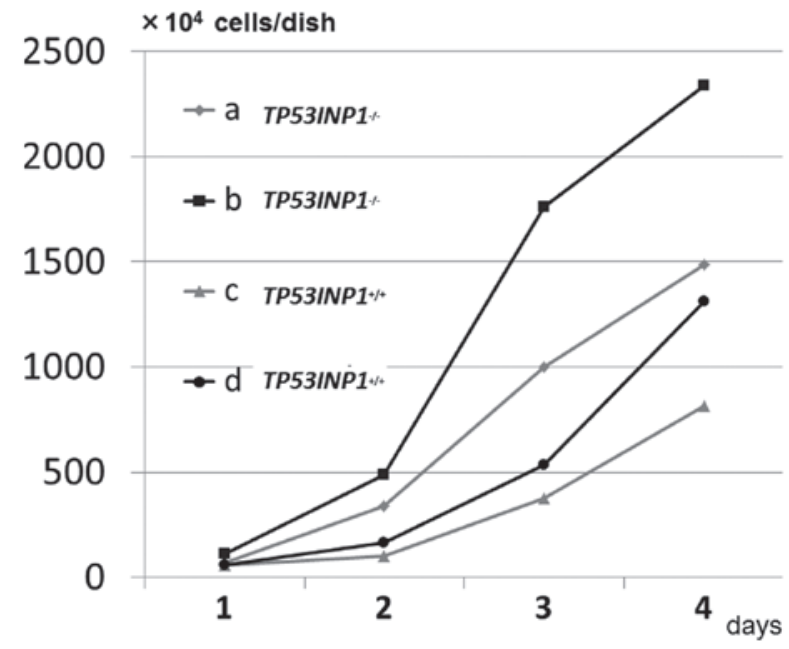

Figure 2. Cell growth curve. TP53INP1 ${ }^{-\leftarrow}$ cells tend to grow faster than TP53INP1 ${ }^{+/+}$cells.

gemcitabine for $24 \mathrm{~h}$. Cell growth was determined using the colony formation assay. The same experiments were performed 3 times. The mean number of colonies in each experiment was calculated.

Statistical analysis. Data were analyzed using the Student's t-test. Values were given as the mean \pm SEM and $\mathrm{P}<0.05$ was considered to indicate a statistically significant difference. The results were analyzed using Excel (Microsoft Corp.).

\section{Results}

Characteristics of TP53INP1-deficient and the wild-type $M E F s$. The TP53INP1, a nuclear localization protein gene, was amplified using PCR. Null mutation mice were gener-

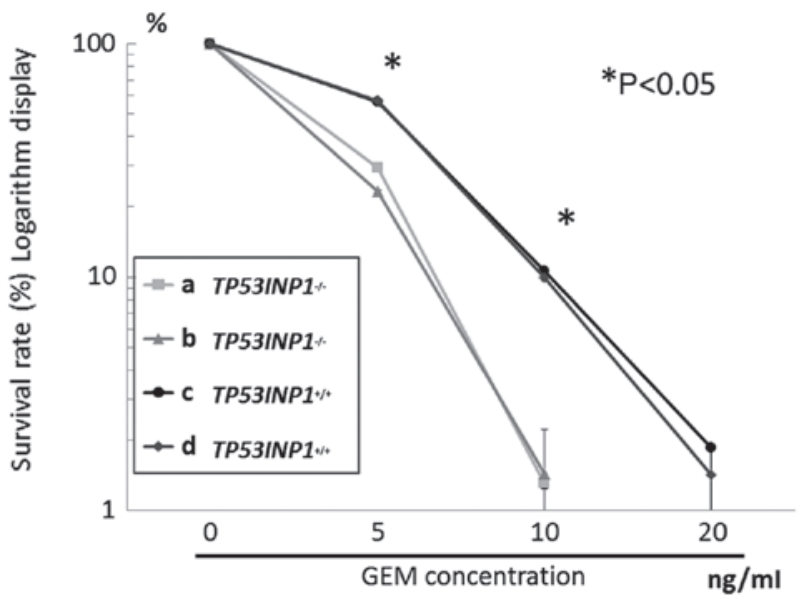

Figure 3. Cell viability after gemcitabine treatment. TP53INP1 ${ }^{-/}$cells were significantly more sensitive to gemcitabine than TP53INP $1^{+/+}$cells $\left({ }^{*} \mathrm{P}<0.05\right)$.

ated by genotyping (18). As confirmed by PCR (Fig. 1A) and western blot analysis, TP53INP1 was deficient in TP53INP1 ${ }^{-1}$ MEFs, but expressed in TP53INP1 ${ }^{+/+}-\mathrm{MEFs}$, respectively (Fig. 1B).

TP53INP1 ${ }^{-1}$-MEFs and TP53INP1 ${ }^{+/+}$-MEFs were cultured and the colonies were confirmed. Subsequently, several subclones were established from the TP53INP1 ${ }^{-1-}$-MEFs and TP53INP1 ${ }^{+/+}$-MEFs. Two subclones from cells of each type (subclones a and b from the TP53INP1 ${ }^{-1}$-MEFs; subclones $\mathrm{c}$ and $\mathrm{d}$ from the TP53INP1 ${ }^{+/+}$-MEFs) were selected.

Proliferation of TP53INPI ${ }^{-/}-M E F s$ and TP53INPI ${ }^{+/+}-M E F s$. Cell proliferation was measured by colony formation assay. The proliferation of TP53INP1 ${ }^{-/}$-MEFs tended to be faster compared to TP53INP1 ${ }^{+++}$-MEFs (a, b and c, d, respectively) (Fig. 2).

Sensitivities of TP53INP1 ${ }^{-1-M E F s}$ and TP53INPI ${ }^{+/+}$-MEFs to gemcitabine. Cells were treated with gemcitabine for $24 \mathrm{~h}$, then cell growth was assayed. Gemcitabine inhibited a significantly greater TP53INP1 ${ }^{-/}$cell growth compared to TP53INP1 ${ }^{+/+}$ cells, in a concentration-dependent manner (Fig. 3) $(\mathrm{P}<0.05)$. According to the curve indicating the survival rate, $\mathrm{IC}_{50}$ of TP53INP1 ${ }^{-1}$ was estimated as $2-3 \mathrm{ng} / \mathrm{ml}$, while that of $\mathrm{TP} 3 \mathrm{INP1}^{+/+}$was $5-10 \mathrm{ng} / \mathrm{ml}$.

Effects of gemcitabine on the cell cycle status of TP53INP1 $1^{-1}$ - MEFs and TP53INP1 $1^{+/+}$-MEFs. TP53INP1 $1^{-/}$-MEFs and TP53INP1 ${ }^{+/+}$-MEFs were treated with gemcitabine at $10 \mathrm{ng} / \mathrm{ml}$ for 24 and $48 \mathrm{~h}$. Subsequent to treatment, each cell cycle status was determined using FCM. Differences in each peak of G1, $\mathrm{S}$ and $\mathrm{G} 2 / \mathrm{M}$ of TP53INP1 $1^{-/}$-MEF and TP53INP1 ${ }^{+/+}$-MEF were impossible to confirm based on the results of FCM. Gemcitabine treatment generated almost equal apoptosis in both cell lines.

p21 and p53 expression in TP53INP1 $1^{-1-M E F s ~ a n d ~}$ TP53INP1 $1^{+/+}$-MEFs. A previous report (16) demonstrated that TP53INP1 overexpression induced p21 expression, while findings of the present study confirmed the decrease of the 


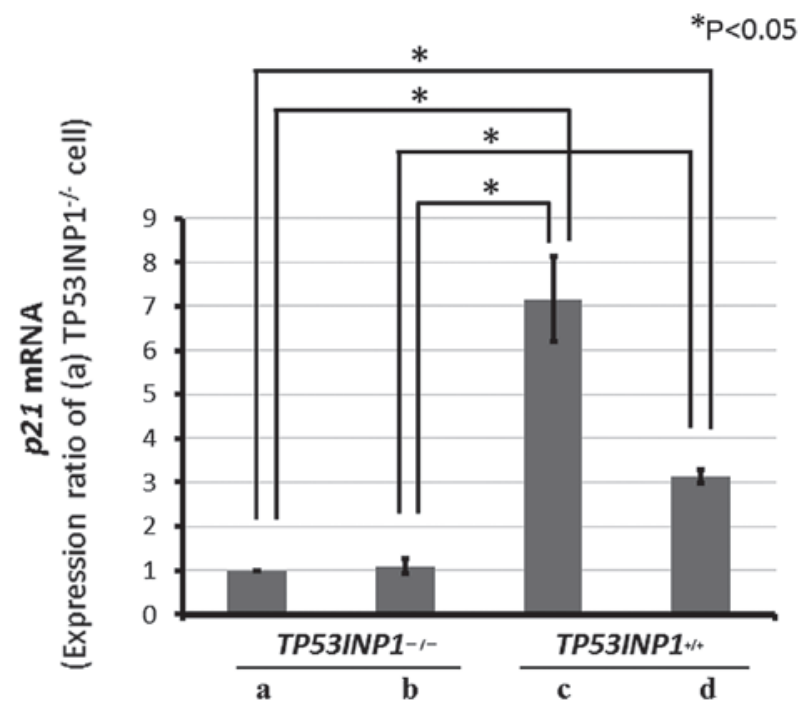

Figure 4. Real-time RT-PCR for p21mRNA. Real-time RT-PCR shows a significant decrease in p21 mRNA expression in (a and b) TP53INP1 ${ }^{-/-}$cells, compared to (c and d) TP53INP1 ${ }^{+/+}$cells $($( $\mathrm{P}<0.05)$.

A

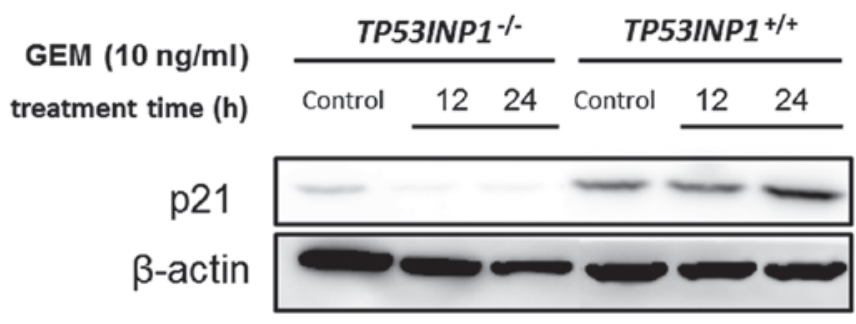

B

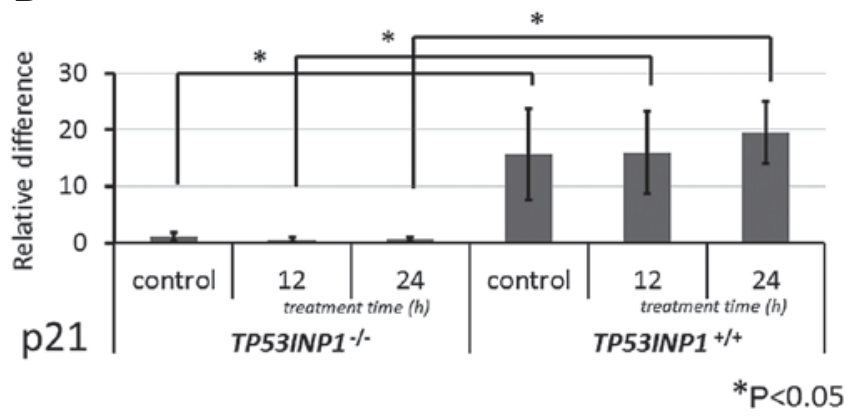

Figure 5. (A) Western blot analysis of $\mathrm{p} 21$ expression. TP53INP1 ${ }^{-/}$cells do not express p21, although TP53INP1 ${ }^{+/+}$cells show p21 expression treatment with gemcitabine. (B) The $\mathrm{p} 21$ protein revelation amount is analyzed quantitatively. The expression of p21 decreases significantly in both TP53INP1 ${ }^{-/}$and TP53INP1 ${ }^{+/+}$cells $\left({ }^{*} \mathrm{P}<0.05\right)$.

mRNA and protein expressions induced by the TP53INP1 knockout. Moreover, another study described that oxidative stress decreased the p21 expression in TP53INP1 knockout cells; thus, the change in p21 expression was examined using gemcitabine treatment.

Subsequent to gemcitabine treatment in both cell lines, in RT-PCR, the p21 mRNA expression was significantly decreased in the TP53INP1 ${ }^{-/}$-MEFs compared to TP53INP1 ${ }^{+/+}$ MEFs $(\mathrm{P}<0.05)$ (Fig. 4).

Subsequent to the same treatment in both cell lines, western blot analysis revealed that the protein expression of

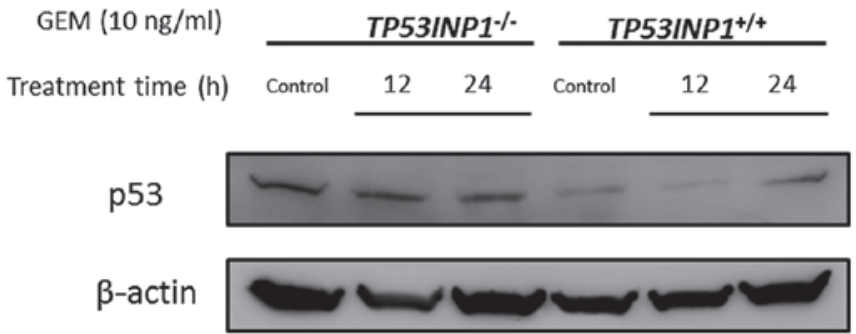

Figure 6. Western blot analysis of p53 expression. Western blot analysis shows no change in p53 expression in either $\mathrm{TP} 3 \mathrm{INP}^{-/-}$or $\mathrm{TP}^{2} 3 \mathrm{INP} 1^{+/+}$ cells, subsequent to gemcitabine treatment.

p21 was significantly lower in TP53INP1 ${ }^{-/-}$-MEFs compared to TP53INP1 $1^{+/+}$-MEFs $(\mathrm{P}<0.05)$ (Fig. 5).

It is already widely acknowledged that p53 is located upstream of $\mathrm{p} 21$. A previous study described that a decreased p21 expression resulted from a decreased p53 expression (21). In TP53INP1 ${ }^{-/}$cells, the p21 expression decreased in RNA and protein. Whether or not these results were derived from the status of p53 expression was investigated. The expression of p53 was verified by western blotting in both TP53INP1 ${ }^{-1-}$ -MEF and TP53INP1 ${ }^{+/+}-\mathrm{MEF}$. This experiment demonstrated that $\mathrm{p} 53$ expression was not decreased in TP53INP1 ${ }^{-/}-\mathrm{MEFs}$ (Fig. 6).

\section{Discussion}

This study is the first addressing the role of TP53INP1 in the molecular mechanisms of gemcitabine sensitivity.

TP53INP1 is considered to suppress cell proliferation, while reducing gemcitabine sensitivity, since TP53INP1 $1^{--}$-MEF proliferation is faster and gemcitabine sensitivity of $\mathrm{INP}^{-/}$is higher compared to the wild-type MEFs. Flow cytometry analysis indicated no existing difference between $\mathrm{INP}^{+/+}$and $\mathrm{INP} 1^{-/-}$in the cell-cycle-checkpoint. It is known that DNA replication processes with disrupted DNA repair leads to unsuccessful cell proliferation. Moreover, TP53INP1 is known to be a pro-apoptosis gene. An earlier study demonstrated that TP53INP1 expression is induced by gemcitabine treatment in a pancreatic cancer cell line, PANC-1 (15).

The gemcitabine action was expected to be stronger in the $\mathrm{INP}^{+/+}$compared to INP1 ${ }^{-/-}$cells, the results, however, revealed the opposite. This phenomenon differed from those delineated in previous studies on gemcitabine sensitivity in pancreatic cancer, since the cells used were immortalized MEF instead of pancreatic cancer cells. TP53INP1 has a tumor suppressor gene character, while TP53INP1 expression is decreased in cancer cells (20), while being decreased or eradicated in the course of pancreatic carcinogenesis (14). In this study, the p21 expression was delineated to be suppressed and no change was observed subsequent to gemcitabine treatment in $\mathrm{INP}^{-/-}$cells, thereby not contradicting the p21 suppression in INP1 ${ }^{-/}$cells treated with antioxidant stresses (21). These phenomena suggest that decreased or disrupted functions of the check points engender a rapid cell growth without the arrest of DNA replication at the G2/M phase. Apoptosis might be promoted due to the wrong DNA synthesis, whereas these mechanisms might partially explain gemcitabine sensitivity. 
Regarding p53, results demonstrate p53-independent regulation of TP53INP1 expression in addition to the p53-dependent, confirming that $\mathrm{p} 21$ expression is independent of $\mathrm{p} 53$.

The INP $1^{-/}$cells grew more rapidly compared to the $\mathrm{INP} 1^{+/+}$ cells. $\mathrm{Rb}$ phosphorylation was considered to be involved in this phenomenon. A preliminarily analysis of the expression of $\mathrm{Rb}$ protein and its phosphorylation was conducted, however, no phosphorylation of $\mathrm{Rb}$ was found in the $\mathrm{INP}^{+/+}$and $\mathrm{INP}^{-/-}$cells (data not shown). When Rb is phosphorylated, p21 induces G2 arrest and inhibits DNA replication (22). In the present study, no difference was found between INP1 $1^{+/+}$and INP1 $1^{-/}$cells in the cell-cycle-checkpoint. The activity of TP53INP1, however, should be analyzed at each cell-cycle-checkpoint, based on the information presented above.

Notably,SMG-1, aphosphatidylinositol3-kinase(PI3K), has recently been found to be involved in the gemcitabine-induced expression mechanism of microRNA-155/BIC in pancreatic PANC-1 cancer cells (23). As described above, TP53INP1 is suppressed by microRNA-155/BIC in pancreatic carcinogenesis (14), while microRNA-155 is considered to be associated with gemcitabine sensitivity. Consequently, the correlation among TP53INP1, microRNA-155 and gemcitabine sensitivity requires to be further investigated.

Additional studies are required regarding the role of TP53INP1 in the molecular mechanisms of gemcitabine sensitivity, including that of micro-RNA.

\section{Acknowledgements}

This study was supported in part by the Grant for Collaborative Research from the Kanazawa Medical University (C2008-3) and by the Project Research Grant from the High-Tech Research Center of Kanazawa Medical University (H2010-11).

\section{References}

1. Vincent A, Herman J, Schulick R, Hruban RH and Goggins M: Pancreatic cancer. Lancet 378: 607-620, 2011.

2. Hezel AF, Kimmelman AC, Stanger BZ, Bardeesy N and Depinho RA: Genetics and biology of pancreatic ductal adenocarcinoma. Genes Dev 20: 1218-1249, 2006.

3. Di Marco M, Di Cicilia R, Macchini M, Nobili E, Vecchiarelli S, Brandi G and Biasco G: Metastatic pancreatic cancer: Is gemcitabine still the best standard treatment? Oncol Rep 23: 1183-1192, 2010.

4. Huang P, Chubb S, Hertel LW, Grindey GB and Plunkett W: Action of 2',2'-difluorodeoxycytidine on DNA synthesis. Cancer Res 51: 6110-6117, 1991.

5. Gandhi V, Mineishi S, Huang P, Yang Y, Chubb S, Chapman AJ, Nowak BJ, Hertel LW and Plunkett W: Difluorodeoxyguanosine: cytotoxicity, metabolism, and actions on DNA synthesis in human leukemia cells. Semin Oncol 22: 61-67, 1995.

6. Heinemann V, Xu YZ, Chubb S, Sen A, Hertel LW, Grindey GB and Plunkett W: Inhibition of ribonucleotide reduction in CCRF-CEM cells by 2',2'-difluorodeoxycytidine. Mol Pharmacol 38: 567-572, 1990.

7. Keim V, Iovanna JL and Dagorn JC: The acute phase reaction of the exocrine pancreas. Gene expression and synthesis of pancreatitis-associated proteins. Digestion 55: 65-72, 1994.
8. Xie MJ, Motoo Y, Iovanna JL, Su SB, Ohtsubo K, Matsubara F and Sawabu N: Overexpression of pancreatitis-associated protein (PAP) in human pancreatic ductal adenocarcinoma. Dig Dis Sci 48: 459-464, 2003

9. Motoo Y, Satomura Y, Mouri I, Mouri H, Ohtsubo K, Sakai J, Fujii T, Taga H, Yamaguchi Y, Watanabe H, et al: Serum levels of pancreatitis-associated protein in digestive diseases with special reference to gastrointestinal cancers. Dig Dis Sci 44: 1142-1147, 1999.

10. Su SB, Motoo Y, Iovanna JL, Xie MJ and Sawabu N: Effect of camostat mesilate on the expression of pancreatitis-associated protein (PAP), p8, and cytokines in rat spontaneous chronic pancreatitis. Pancreas 23: 134-140, 2001.

11. Nowak J, Tomasini R, Mattei MG, Azizi Samir LA, Dagorn JC, Dusetti N, Iovanna JL and Pébusque MJ: Assignment of tumor protein p53 induced nuclear protein 1 (TP53INP1) gene to human chromosome band $8 \mathrm{q} 22$ by in situ hybridization. Cytogenet Genome Res 97: 140E, 2002.

12. Tomasini R, Samir AA, Pebusque MJ, Calvo EL, Totaro S, Dagorn JC, Dusetti NJ and Iovanna JL: P53-dependent expression of the stress-induced protein (SIP). Eur J Cell Biol 81: 294-301, 2002.

13. Okamura S, Arakawa H, Tanaka T, Nakanishi H, Ng CC, Taya Y, Monden M and Nakamura Y: p53DINP1, a p53-inducible gene, regulates p53-dependent apoptosis. Mol Cell 8: 85-94, 2001.

14. Gironella M, Seux M, Xie MJ, Cano C, Tomasini R, Gommeaux J, Garcia S, Nowak J, Yeung ML, Jeang KT, et al: Tumor protein 53-induced nuclear protein 1 expression is repressed by miR-155, and its restoration inhibits pancreatic tumor development. Proc Natl Acad Sci USA 104: 16170-16175, 2007.

15. Jiang PH, Motoo Y, Sawabu N and Minamoto T: Effect of gemcitabine on the expression of apoptosis-related genes in human pancreatic cancer cells. World J Gastroenterol 12: 1597-1602, 2006.

16. Möller A, Sirma H, Hofmann TG, Rueffer S, Klimczak E, Dröge W, Will H and Schmitz ML: PML is required for homeodomain-interacting protein kinase 2 (HIPK2)-mediated p53 phosphorylation and cell cycle arrest but is dispensable for the formation of HIPK domains. Cancer Res 63: 4310-4314, 2003.

17. Yoshida K, Liu H and Miki Y: Protein kinase $\mathrm{C}$ delta regulates Ser46 phosphorylation of p53 tumor suppressor in the apoptotic response to DNA damage. J Biol Chem 281: 5734-5740, 2006.

18. Gommeaux J, Cano C, Garcia S, Gironella M, Pietri S, Culcasi M, Pébusque MJ, Malissen B, Dusetti N, Iovanna J and Carrier A: Colitis and colitis-associated cancer are exacerbated in mice deficient for tumor protein 53-induced nuclear protein 1 . Mol Cell Biol 27: 2215-2228, 2007.

19. Harvey M, Sands AT, Weiss RS, Hegi ME, Wiseman RW, Pantazis P, Giovanella BC, Tainsky MA, Bradley A and Donehower LA: In vitro growth characteristics of embryo fibroblasts isolated from p53-deficient mice. Oncology 8: 2457-2467, 1993.

20. Jiang PH, Motoo Y, Garcia S, Iovanna JL, Pébusque MJ and Sawabu N: Down-expression of tumor protein p53-induced nuclear protein 1 in human gastric cancer. World J Gastroenterol 12: 691-696, 2006.

21. Cano CE, Gommeaux J, Pietri S, Culcasi M, Garcia S, Seux M, Barelier S, Vasseur S, Spoto RP, Pébusque MJ, et al: Tumor protein 53-induced nuclear protein 1 is a major mediator of p53 antioxidant function. Cancer Res 69: 219-226, 2009.

22. Niculescu AB III, Chen X, Smeets M, Hengst L, Prives C and Reed SI: Effects of p21Cip1/Waf1) at both the G1/S and the G2/M cell cycle transitions: $\mathrm{pRb}$ is a critical determinant in blocking DNA replication and in preventing endoreduplication. Mol Cell Biol 18: 629-643, 1998.

23. Xia QS, Ishigaki Y, Zhao X, Shimasaki T, Nakajima $H$, Nakagawa H, Takegami T, Chen ZH and Motoo Y: Human SMG-1 is involved in gemcitabine-induced primary microRNA155/BIC up-regulation in human pancreatic cancer PANC-1 cells. Pancreas 40: 55-60, 2011. 